\title{
BMJ
}

\section{Career progression and destinations, comparing men and women in the NHS: postal questionnaire surveys}

\author{
Kathryn S Taylor, research officer Trevor W Lambert, statistician Michael J Goldacre, professor of public \\ health
}

UK Medical Careers Research Group, Unit of Health-Care Epidemiology, Department of Public Health, Oxford University, Oxford, OX3 7LF

Correspondence to: M Goldacre michael.goldacre@dphpc.ox.ac.uk

Cite this as: BMJ 2009;338:b1735 doi:10.1136/bmj.b1735

\section{ABSTRACT}

Objective To study the career progression of NHS doctors, comparing men and women.

Design Postal questionnaire surveys.

Participants and setting Graduates of 1977, 1988, and

1993 from all UK medical schools.

Results The response rate was 68\% (7012/10344). Within general practice, $97 \%(1208 / 1243)$ of men, $99 \%$ $(264 / 267)$ of women who had always worked full time throughout their career, and 87\% (1083/1248) of all women were principals. Median times from qualification to principal status were 5.8 (95\% confidence interval 5.6 to 6.0) years for men, 5.6 (5.4 to 5.8) years for women who had worked full time during training, and 6.8 (6.5 to 7.0) years for all women. Of the 1977 and 1988 graduates in hospital practice, $96 \%$ (1293/1347) of men were consultants, compared with $92 \%$ (276/299) of women who had always worked full time throughout their career and $67 \%(277 / 416)$ of women who had not. Median time to first consultant post was 11.7 (11.5 to 11.9) years for men, 11.3 (11.0 to 11.6) years for women who worked ful time during training, and 12.3 (12.0 to 12.6) years for all women. Women who had not always worked full time throughout their career were over-represented in general practice and under-represented in most hospital specialties, substantially so in the surgical specialties and anaesthetics. Women who had always worked full time were under-represented not only in the surgical specialties but also in general practice.

Conclusions Women not progressing as far and as fast as men was, generally, a reflection of not having always worked full time rather than their sex. The findings suggest that women do not generally encounter direct discrimination; however, the possibility that indirect discrimination, such as lack of opportunities for part time work, has influenced choice of specialty cannot be ruled out.

\section{INTRODUCTION}

Doctors spend many years in postgraduate training. In the past, doctors in hospital practice in the United Kingdom typically did not attain their first consultant post until their mid to late 30s. For example, in the 1980 s, the mean age at first consultant appointment was 37 years. ${ }^{1}$ Reforms to specialist training in the 1990s were intended to shorten the training period, but it is still many years even so. ${ }^{23}$ Lengthy training periods present potential difficulties for women who wish to start a family. Motherhood and other caring responsibilities may entail switching from full time to part time work, which will inevitably prolong training.

In addition to the challenges of pursuing a medical career when raising a family, female doctors sometimes report encountering discrimination and barriers to their careers. ${ }^{4-6}$ Discrimination may be direct, as when decisions are made that favour men rather than women, or indirect, as when women perceive that a career pathway is too difficult for them to pursue because of, for example, a male dominated work culture, sex stereotypes, unsocial hours, or informal patronage that favours men. ${ }^{4}$ Some indirect barriers to women, in employment generally, are subtle and include deeply ingrained, and perhaps unconscious, cultural sex schemas that have privileged men. ${ }^{7}$ The male-female composition of some hospital clinical specialties implies that some women are deterred from pursuing careers in them because of anticipated difficulties in achieving a desired work-life balance, a lack of flexible working opportunities, and scarcity of role models. $^{8-14}$

Some of the most striking evidence about impediments to women's careers in medicine comes from studies in the United States and of women in academic careers. ${ }^{15-19}$ Contemporary evidence from the UK is sparser. McManus and Sproston, who reported an analysis of English NHS data, commented that in most specialties "the currently low proportion of women consultants is mostly explained by historically low numbers of women entering medical school a quarter of a century earlier. ${ }^{20}$ In general practice, the differing working patterns of men and women may also have consequences in terms of progression to senior posts, although published research, such as a study in Scotland by McKinstry et al, ${ }^{21}$ focuses more on the impact of increasing numbers of women in medicine on the hours worked per doctor than on the question of career progression.

We report here on the career progression and career destinations of NHS doctors who qualified from UK medical schools in 1977, 1988, and 1993, comparing 
men and women. Our aim was to seek evidence about whether female doctors are disadvantaged in pursuing careers in the NHS.

\section{METHODS \\ Procedure and population}

The UK Medical Careers Research Group has done questionnaire surveys of cohorts of doctors at regular intervals after graduation; each cohort consists of all qualifiers from all UK medical schools in a selected year,. The qualifiers of 1977, 1988, and 1993 form the subject of this paper, as they are the three cohorts in our work programme on whom we sought information about full time and part time working and who have progressed far into their long term careers. Our methods have been reported in detail elsewhere. ${ }^{10}$ The starting point for each survey is the cohort of qualifiers as it was in the first year after qualification (excluding a small number who notify us that they do not wish to participate). For each cohort, the General Medical Council (GMC) provided a complete list of the qualifiers and their addresses. In successive surveys of each cohort, we have tried to trace all the surviving members of the original cohort. Updated addresses came from the respondents themselves in their replies to previous surveys, from the GMC, and from the Medical Directory.

\section{Survey instrument, definitions, and data analysis}

The standard questionnaire that we use covers a broad range of topics including past employment, current employment, future career plans, and whether the respondent had always worked full time. We confined the analysis to respondents working in the UK NHS (including those with an honorary NHS contract, who are predominantly in clinical academic posts). We analysed data separately for doctors who pursued careers in general practice and in hospital practice.
For the purpose of this paper, we considered the first appointment as a hospital consultant or general practice principal to mark the attainment of a senior position as an independent practitioner. We calculated times from qualification to first appointment by using replies to the question: "If you have attained either of these career milestones [consultant or principal], please give the date first reached . . . (Enter month and year in digits.)" In calculating percentages of respondents who had achieved senior posts, we identified those in senior posts from the above replies and the respondents' current grade. For the purposes of this analysis, we considered salaried general practitioners to have attained principal status and hospital medical directors to have reached consultant status.

To identify respondents who had worked continuously full time, we asked: "Since qualifying as a doctor, have you always worked full time?" Doctors who had not always worked full time included those who, for at least some of their career, had worked part time and those who had taken career breaks. For the analysis of times to reach career milestones, we used employment data from our other surveys to reclassify as "full time when in training" those respondents whose only part time working was after reaching their career milestone. For brevity, we use the term "full time" to refer to doctors who had continuously worked full time and "part time" for those who had not. We refer to doctors who always worked full time throughout their careers and those who had not when discussing career destinations (tables 1, 2, 3, and 7), and we refer to doctors who had always worked full time during their training and those who had not for the analysis of times to reach career milestones (tables 4, 5, and 6).

We use the terms under-representation of women (or of women working full time) and over-representation to refer to significantly lower and higher percentages of women (or of women working full time)

Table 1/Characteristics of NHS doctors working in general practice and hospital practice: men and women split by working pattern throughout their careers, and by having or not having children. Values are percentages (numbers)

\begin{tabular}{|c|c|c|c|c|c|c|c|c|}
\hline \multirow[b]{2}{*}{ Cohorts } & \multicolumn{4}{|c|}{ Women } & \multicolumn{4}{|c|}{ Men } \\
\hline & Always full time & $\begin{array}{l}\text { Not always full } \\
\text { time }\end{array}$ & With children & With no children & Always full time & $\begin{array}{l}\text { Not always full } \\
\text { time }\end{array}$ & With children & With no children \\
\hline \multicolumn{9}{|c|}{ In general practice: } \\
\hline 1977 & $27.1(85)$ & 72.9 (229) & NR & NR & $90.0(486)$ & $10.0(54)$ & NR & NR \\
\hline 1988 & $20.8(102)$ & $79.2(388)$ & $87.3(434)$ & $12.7(63)$ & 84.5 (349) & $15.5(64)$ & $86.4(361)$ & $13.6(57)$ \\
\hline 1993 & $18.6(80)$ & 81.4 (349) & 73.7 (320) & $26.3(114)$ & $73.3(203)$ & $26.7(74)$ & $78.6(217)$ & $21.4(59)$ \\
\hline All & $21.7(267)$ & $78.3(966)$ & $81.0(754)$ & $19.0(177)$ & $84.4(1038)$ & $15.6(192)$ & $83.3(578)$ & $16.7(116)$ \\
\hline \multicolumn{9}{|c|}{ In hospital practice: } \\
\hline 1977 & $40.3(102)$ & 59.7 (151) & NR & NR & $91.4(614)$ & $8.6(58)$ & NR & NR \\
\hline 1988 & $42.6(197)$ & $57.4(265)$ & 74.4 (358) & $25.6(123)$ & $94.3(617)$ & $5.7(37)$ & 81.9 (543) & $18.1(120)$ \\
\hline 1993 & $50.7(271)$ & $49.3(264)$ & $60.7(326)$ & $39.3(211)$ & 93.5 (675) & $6.5(47)$ & $67.2(487)$ & $32.8(238)$ \\
\hline All & $45.6(570)$ & $54.4(680)$ & $67.2(684)$ & $32.8(334)$ & 93.1 (1906) & $6.9(142)$ & 74.2 (1030) & $25.8(358)$ \\
\hline Total & 33.7 (837) & $66.3(1646)$ & 73.8 (1438) & $26.2(511)$ & 89.8 (2944) & $10.2(334)$ & 77.2 (1608) & $22.8(474)$ \\
\hline
\end{tabular}

$\mathrm{NR}=$ not recorded

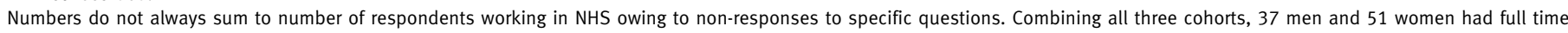
status missing. Excluding the 1977 cohort (for which we did not collect data on children), three men and three women had children status missing.

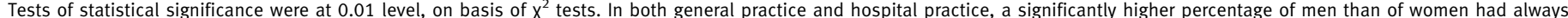

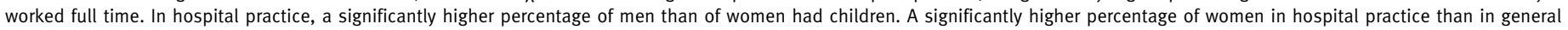
practice had always worked full time. A significantly higher percentage of women in general practice than in hospital practice had children. 

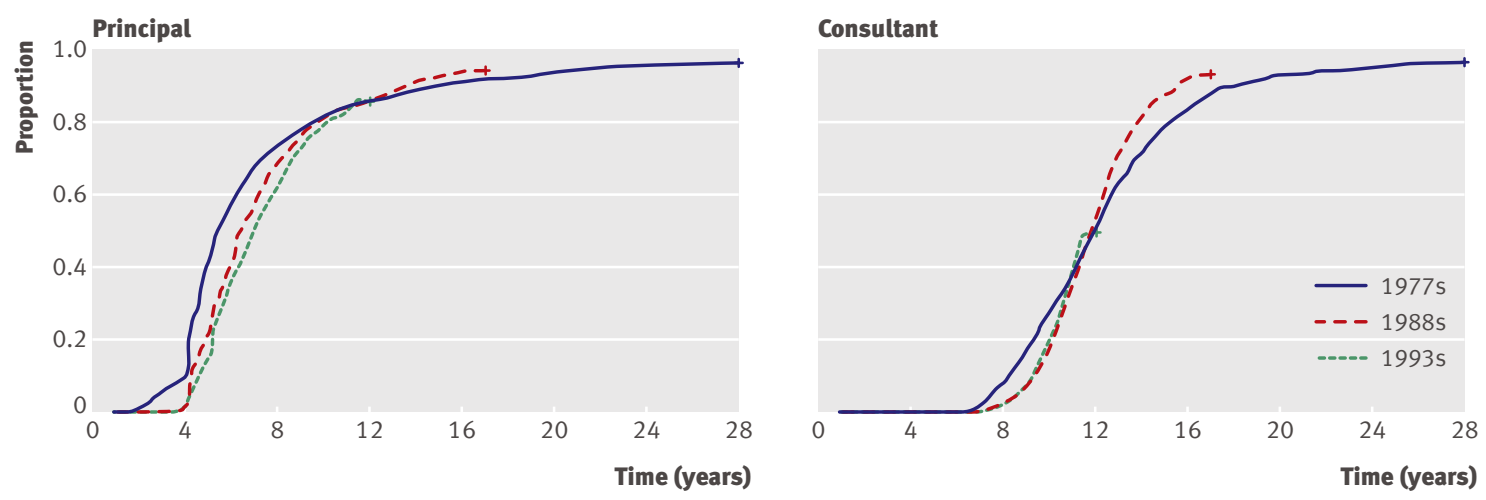

Fig 1| Time after qualification to senior NHS posts, split by cohort. +=censored

compared with men. Similarly, under-representation and over-representation of women working part time refers to a comparison between women who had always worked full time and women who had worked part time.

In surveys of the 1988 and 1993 cohorts, we asked: "How many children under 16 are normally resident in your household?" We used the replies from successive surveys to group the respondents into those who had ever had children under 16 in their household and those who had not.

We compared the career progression of men and women, full time and part time doctors, and those with and without children. We used descriptive statistics to summarise response rates and demographic data. We did $\chi^{2}$ tests and Fisher's exact tests to compare different subgroups of doctors.

We compared times to reach career milestones by using Kaplan-Meier survival analysis. In analysing times to reach general practice principal posts, we included all respondents working in NHS general practice at the time of the latest survey. We censored (the observation period was cut off before the event occurred $^{22}$ ) those who left NHS general practice, taking the censoring time as the year after the last year they were known to be in NHS general practice. In analysing times to reach hospital consultant posts, we included all respondents working in NHS hospital practice at the time of the latest survey, censoring those who left NHS hospital practice by taking the censoring time as the year after the last year they were known to be in NHS hospital practice. We used the log rank (Mantel-Cox) test to compare groups for equality of the distribution of times to reach senior posts (survival time distributions in Kaplan-Meier terminology, which in our context are "time distributions to senior posts"). In making multiple similar comparisons, we regarded the attainment of a significance threshold of $\mathrm{P} \leq 0.01$ as evidence of a significant difference.

\section{RESULTS}

Response rates and demographics

In the UK, 3135 doctors qualified in 1977, 3739 in 1988 , and 3671 in 1993. The most recent surveys of these cohorts were done in 2004 and 2005. Excluding

Table 2|Career destinations of men and women: percentage of NHS respondents in general practice who had achieved principal status and percentage of NHS respondents in hospital practice who had achieved consultant status, split by working pattern throughout their careers. Values are percentages (numbers)

\begin{tabular}{|c|c|c|c|c|c|c|c|c|}
\hline & \multicolumn{2}{|c|}{ Combined cohorts* } & \multicolumn{2}{|c|}{1977 graduates } & \multicolumn{2}{|c|}{1988 graduates } & \multicolumn{2}{|c|}{1993 graduates } \\
\hline & Men & Women & Men & Women & Men & Women & Men & Women \\
\hline \multicolumn{9}{|c|}{ Achieved general practice principal status } \\
\hline All & $\begin{array}{c}97.2 \\
(1208 / 1243) \dagger\end{array}$ & $\begin{array}{c}86.8 \\
(1083 / 1248) \dagger\end{array}$ & $\begin{array}{c}99.5 \\
(545 / 548) \dagger\end{array}$ & $\begin{array}{c}94.3 \\
(298 / 316) \dagger\end{array}$ & $\begin{array}{c}97.1 \\
(406 / 418) \dagger\end{array}$ & $\begin{array}{c}89.4 \\
(445 / 498) \dagger\end{array}$ & $\begin{array}{c}92.8 \\
(257 / 277) \dagger\end{array}$ & $\begin{array}{c}78.3 \\
(340 / 434) \dagger\end{array}$ \\
\hline Always full time & $\begin{array}{c}98.6 \\
(1023 / 1038) \ddagger\end{array}$ & $\begin{array}{c}98.9 \\
(264 / 267) \ddagger\end{array}$ & $\begin{array}{c}99.8 \\
(485 / 486)\end{array}$ & $\begin{array}{c}100.0 \\
(85 / 85)\end{array}$ & $\begin{array}{c}98.6 \\
(344 / 349)\end{array}$ & $\begin{array}{c}100.0 \\
(102 / 102) \ddagger\end{array}$ & $\begin{array}{c}95.6 \\
(194 / 203) \ddagger\end{array}$ & $\begin{array}{c}96.3 \\
(77 / 80) \ddagger\end{array}$ \\
\hline Not always full time & $\begin{array}{c}91.1 \\
(175 / 192) \dagger \ddagger\end{array}$ & $\begin{array}{c}83.9 \\
(810 / 966) \dagger \ddagger\end{array}$ & $\begin{array}{c}96.3 \\
(52 / 54)\end{array}$ & $\begin{array}{c}92.6 \\
(212 / 229)\end{array}$ & $\begin{array}{c}93.8 \\
(60 / 64)\end{array}$ & $\begin{array}{c}87.6 \\
(340 / 388) \ddagger\end{array}$ & $\begin{array}{c}85.1 \\
(63 / 74) \ddagger\end{array}$ & $\begin{array}{c}73.9 \\
(258 / 349) \ddagger\end{array}$ \\
\hline \multicolumn{9}{|c|}{ Achieved consultant status } \\
\hline All & $\begin{array}{c}96.0 \\
(1293 / 1347)+\S\end{array}$ & $\begin{array}{c}74.7 \\
(559 / 748) \dagger\end{array}$ & $\begin{array}{c}96.8 \\
(660 / 682) \dagger\end{array}$ & $\begin{array}{c}72.6 \\
(193 / 266) \dagger\end{array}$ & $\begin{array}{c}95.2 \\
(633 / 665)+\S\end{array}$ & $\begin{array}{c}75.9 \\
(366 / 482) \dagger\end{array}$ & $\begin{array}{c}47.4 \\
(344 / 725)\end{array}$ & $\begin{array}{c}42.4 \\
(228 / 538)\end{array}$ \\
\hline Always full time & $\begin{array}{c}97.1 \\
(1195 / 1231) \dagger \ddagger\end{array}$ & $\begin{array}{c}92.3 \\
(276 / 299) \dagger \neq \S\end{array}$ & $\begin{array}{c}97.2 \\
(597 / 614) \\
\end{array}$ & $\begin{array}{c}96.1 \\
(98 / 102) \ddagger\end{array}$ & $\begin{array}{c}96.9 \\
(598 / 617) \dagger \ddagger\end{array}$ & $\begin{array}{c}90.4 \\
(178 / 197) \dagger \neq \S\end{array}$ & $\begin{array}{c}48.7 \\
(329 / 675)\end{array}$ & $\begin{array}{c}52.4 \\
(142 / 271) \ddagger\end{array}$ \\
\hline Not always full time & $\begin{array}{c}87.4 \\
(83 / 95) \dagger \ddagger\end{array}$ & $\begin{array}{c}66.6 \\
(277 / 416) \dagger \ddagger\end{array}$ & $\begin{array}{c}94.8 \\
(55 / 58) \dagger\end{array}$ & $\begin{array}{c}60.3 \\
(91 / 151) \dagger \ddagger\end{array}$ & $\begin{array}{c}75.7 \\
(28 / 37) \ddagger\end{array}$ & $\begin{array}{c}70.2 \\
(186 / 265) \ddagger\end{array}$ & $\begin{array}{c}29.8 \\
(14 / 47)\end{array}$ & $\begin{array}{c}32.2 \\
(85 / 264) \ddagger\end{array}$ \\
\hline
\end{tabular}

*1977 and 1988 cohorts for consultants and all three cohorts for general practice principals.

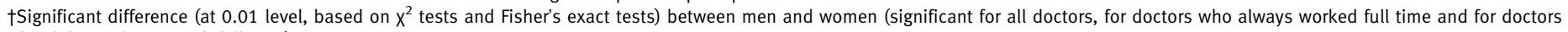
who did not always work full time).

$\ddagger$ Significant difference between doctors who always worked full time and those who did not always work full time (significant for men and for women).

$\S$ Significant difference between women who always worked full time and all men. 
deaths (92 doctors), those who declined to participate (coincidentally, also 92 doctors), and those who never registered (16 doctors), the effective response rates were $72 \%(2180 / 3045)$ for the 1977 cohort, 69\% (2521/3675) for the 1988 cohort, and 64\% (2311/ $3625)$ for the 1993 cohort. For the cohorts combined, the effective response rates were $65 \%(3876 / 5987)$ for men, $72 \%$ (3136/4357) for women (we did not know the sex of one of the 1993 qualifiers who did not reply to the most recent survey), and 68\% (7012/10344) overall. The median age of the doctors in NHS general practice and hospital practice, at the time of their survey, was 51 years for the 1977 cohort, 40 for the 1988 cohort, and 35 for the 1993 cohort. Of the 7012 respondents, $6019(85.8 \%)$ were working in the NHS at the time of the surveys (men $86.7 \%$ (3359/3876), women $84.8 \%(2660 / 3136))$.

Full time work, part time work, and children

Of the 5849 NHS doctors working in general practice or hospital practice, 5761 indicated whether they had always worked full time throughout their careers; $34 \%$ $(\mathrm{n}=837)$ of the women and $90 \%$ (2944) of the men had done so $(\mathrm{P}<0.001)$ (table 1$)$. The percentage of women in NHS general practice who had always worked full time fell from $27 \%$ for the 1977 cohort to $19 \%$ for the 1993 cohort $(\mathrm{P}=0.008)$. The percentage of women in NHS hospital practice who had always worked full time increased from $40 \%$ for the 1977 cohort to $51 \%$ for the 1993 cohort $(\mathrm{P}=0.008)$.

Of 4031 NHS doctors in the 1988 and 1993 cohorts working in general practice or hospital practice who told us whether they had children, $74 \%(\mathrm{n}=1438)$ of the women and $77 \%(1608)$ of the men had children in their household $(\mathrm{P}=0.01) ; 81 \%$ of women in general practice had children, compared with $67 \%$ of the women in hospital practice $(\mathrm{P}<0.001)$, and $83 \%$ of men in general practice had children, compared with $74 \%$ of men in hospital practice $(\mathrm{P}<0.001)$. In general practice, we found no significant difference $(\mathrm{P}=0.3)$ between the percentage of women with children $(81 \%)$ and the percentage of men with children (83\%). In hospital practice, a significantly higher percentage of men $(74 \%)$ than of women $(67 \%)$ had children $(\mathrm{P}<0.001)$.

\section{Appointment to general practice principal and hospital consultant posts}

In all three cohorts, higher percentages of men than women had achieved general practice principal and hospital consultant status by the time of the most recent surveys (table 2). The differences in attainment between men and women were substantially reduced when we made comparisons between women who had always worked full time throughout their career and men. Of all doctors in general practice, those who were principals comprised $97 \%$ of all men, $87 \%$ of all women, and $99 \%$ of full time working women (men $v$ women, $\mathrm{P}<0.001$; men $v$ full time working women, $\mathrm{P}=0.2$ ). For all doctors in hospital practice, $96 \%$ of men, $75 \%$ of all women, and $92 \%$ of full time working women were consultants (men $v$ women, $\mathrm{P}<0.001$; men $v$ full time working women, $\mathrm{P}=0.01)$. The difference between men and full time working women was

Table 3 |Career destinations of men and women: percentage of NHS respondents in general practice who had achieved principal status, and percentage of NHS respondents in hospital practice who had achieved consultant status, split by having or not having children and by working pattern throughout their careers. Values are percentages (numbers)

\begin{tabular}{|c|c|c|c|c|}
\hline & \multicolumn{2}{|c|}{1988 graduates } & \multicolumn{2}{|c|}{1993 graduates } \\
\hline & Men & Women & Men & Women \\
\hline \multicolumn{5}{|l|}{ Achieved general practice principal status } \\
\hline All & $97.1(406 / 418)^{*}$ & $89.4(445 / 498)^{\star}$ & $92.8(257 / 277)^{\star}$ & $78.3(340 / 434)^{*}$ \\
\hline With children & $98.6(356 / 361)^{\star} \dagger$ & $88.0(382 / 434)^{\star} \dagger$ & $94.5(205 / 217)^{\star}$ & $74.7(239 / 320)^{\star} \dagger$ \\
\hline No children & $87.7(50 / 57) \dagger$ & $98.4(62 / 63) \dagger$ & $86.4(51 / 59)$ & $88.6(101 / 114) \dagger$ \\
\hline Always worked full time and had children & $99.4(310 / 312) \dagger$ & $100.0(71 / 71)$ & $97.0(160 / 165)$ & $100.0(35 / 35)$ \\
\hline Always worked full time and had no children & $91.9(34 / 37) \dagger$ & $100.0(31 / 31)$ & $89.5(34 / 38)$ & $93.3(42 / 45)$ \\
\hline Did not always work full time and had children & $93.6(44 / 47)$ & $86.8(309 / 356)$ & $86.5(45 / 52)$ & $71.2(200 / 281)$ \\
\hline Did not always work full time and had no children & $94.1(16 / 17)$ & $96.8(30 / 31)$ & $81.0(17 / 21)$ & $85.3(58 / 68)$ \\
\hline \multicolumn{5}{|l|}{ Achieved consultant status } \\
\hline All & $95.2(633 / 665)^{\star} \ddagger$ & $75.9(366 / 482)^{\star}$ & $47.4(344 / 725)$ & $42.4(228 / 538)$ \\
\hline With children & $96.3(523 / 543)^{*} \dagger$ & $74.9(268 / 358)^{\star}$ & $50.7(247 / 487)^{\star}$ & $39.0(127 / 326)^{\star}$ \\
\hline No children & $90.0(108 / 120) \dagger$ & $78.9(97 / 123) \ddagger$ & $40.8(97 / 238)$ & $47.9(101 / 211)$ \\
\hline Always worked full time and had children & $97.5(498 / 511)$ & $93.1(94 / 101)$ & $51.5(239 / 464)$ & $57.0(49 / 86)$ \\
\hline Always worked full time and had no children & $94.2(98 / 104)$ & $87.4(83 / 95)$ & $42.7(90 / 211)$ & $50.5(93 / 184)$ \\
\hline Did not always work full time and had children & $80.0(20 / 25)$ & $72.7(173 / 238)$ & $34.8(8 / 23)$ & $32.2(77 / 239)$ \\
\hline Did not always work full time and had no children & $66.7(8 / 12)$ & $48.1(13 / 27)$ & $25.0(6 / 24)$ & $32.0(8 / 25)$ \\
\hline
\end{tabular}

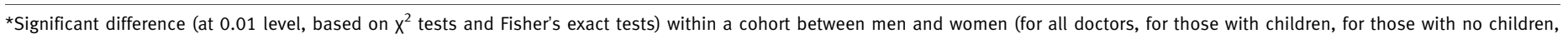

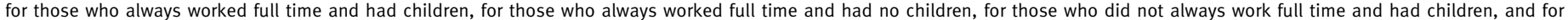
those who did not always work full time and had no children).

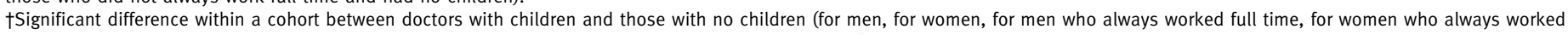
full time, for men who did not always work full time, and for women who did not always work full time).

$\ddagger$ Significant difference within a cohort between women with no children and all men. 
Table 4 |Years from qualifying as doctor to first appointment as NHS general practice principal or hospital consultant split by working pattern during training. Values are median; fastest quarter (number)

\begin{tabular}{|c|c|c|c|c|c|c|c|c|}
\hline & \multicolumn{2}{|c|}{ Combined cohorts* } & \multicolumn{2}{|c|}{1977 graduates } & \multicolumn{2}{|c|}{1988 graduates } & \multicolumn{2}{|c|}{1993 graduates } \\
\hline & Men & Women & Men & Women & Men & Women & Men & Women \\
\hline \multicolumn{9}{|c|}{ Achieved general practice principal status } \\
\hline All & $5.8 ; 4.6+\S(1158)$ & $6.8 ; 5.2 †(1010)$ & $5.1 ; 4.2 \dagger(523)$ & $6.3 ; 4.6 \dagger(282)$ & $6.2 ; 5.1 \dagger \S(394)$ & $6.6 ; 5.2 \dagger(426)$ & $6.7 ; 5.2+\S(241)$ & $7.3 ; 5.6 †(302)$ \\
\hline Always full time & 5.6; 4.6‡ (1095) & $5.6 ; 4.6 \mp \S(610)$ & $5.0 ; 4.2(513)$ & $5.1 ; 4.2 \ddagger(171)$ & $6.2 ; 5.0 \ddagger(368)$ & $5.6 ; 4.6 \mp \S(253)$ & $6.4 ; 5.1 \ddagger(214)$ & $6.0 ; 5.0 \ddagger \S(186)$ \\
\hline Not always full time & $9.8 ; 6.9 \ddagger(56)$ & $9.3 ; 6.9 \ddagger(394)$ & $9.2 ; 7.5(5)$ & $12.5 ; 8.3 \ddagger(110)$ & $10.1 ; 6.7 \ddagger(24)$ & $8.6 ; 6.5 \ddagger(172)$ & $9.8 ; 6.9 \ddagger(27)$ & $8.8 ; 6.9 \ddagger(112)$ \\
\hline \multicolumn{9}{|c|}{ Achieved consultant status } \\
\hline All & $11.7 ; 10.1 †(1269)$ & $12.3 ; 10.5 \dagger(548)$ & 11.9; 9.6† (647) & $12.7 ; 10.1 \dagger(185)$ & $11.7 ; 10.4 \dagger(622)$ & $12.2 ; 10.6+(363)$ & NC; 10.4 (313) & NC; 10.5 (208) \\
\hline Always full time & 11.7; 10.1‡(1243) & 11.3; 10.0‡(382) & $11.8 ; 9.6(632)$ & 11.2; 9.3‡ (131) & $11.7 ; 10.4 \ddagger(611)$ & $11.4 ; 10.1 \ddagger(251)$ & $11.5 ; 10.4$ (308) & $11.2 ; 10.1 \ddagger(171)$ \\
\hline Not always full time & $14.0 ; 12.2 \ddagger(15)$ & $14.7 ; 12.5 \ddagger(162)$ & $13.5 ; 12.2(7)$ & $17.5 ; 14.1 \ddagger(52)$ & $14.2 ; 12.0 \ddagger(8)$ & 13.9; 12.1‡(110) & NC; 10.3 (5) & NC; $11.5 \ddagger(36)$ \\
\hline \multicolumn{9}{|c|}{$\begin{array}{l}\text { NC=median could not be calculated because } 50 \% \text { had not yet become consultants. } \\
\text { ×All three cohorts for general practice principals; } 1977 \text { and } 1988 \text { cohorts for consultants. } \\
\text { †Significant differences (at } 0.01 \text { level, based on log rank tests) between men and women (for all doctors, for doctors who always worked full time during training, and for doctors who did } \\
\text { not always work full time during training). } \\
\text { †Significant differences between doctors who always worked full time during training and those who did not always work full time during training (for men and for women). } \\
\text { §Significant differences between women who always worked full time during training and all men. }\end{array}$} \\
\hline
\end{tabular}

apparent only in the 1988 cohort. In the 1977 cohort of hospital doctors, $97 \%$ of men and $96 \%$ of full time working women were consultants. In the 1993 cohort, $47 \%$ of men and $52 \%$ of full time working women were consultants.

Combining the data from the 1988 and 1993 cohorts in general practice shows that principal status was attained by $99 \%$ of full time working men with children and by $100 \%$ of full time working women with children, by $90 \%$ of part time working men with children and $80 \%$ of part time working women with children, and by $87 \%$ of men with no children and $89 \%$ of part time working women with no children (table 3). Combining the data from the 1988 and 1993 cohorts in hospital practice shows that consultant status was attained by $76 \%$ of full time working men with children and $77 \%$ of full time working women with children, by

$58 \%$ of part time working men with children and 52\% of part time working women with children, and by $39 \%$ of part time working men with no children and 37\% of part time working women with no children (table 3). These findings show that a group of doctors, both men and women, exists who have not always worked full time and who have not achieved consultant status for reasons other than looking after their children.

\section{Time to appointment to consultant and principal posts}

Figure 1 compares the time to appointment to senior posts (Kaplan-Meier "survival" curves) for the three cohorts individually. The curves are similar across the same period after qualification. Overall, men became general practice principals and hospital consultants more quickly than women did (table 4, fig 2). However, comparing the career progression of those
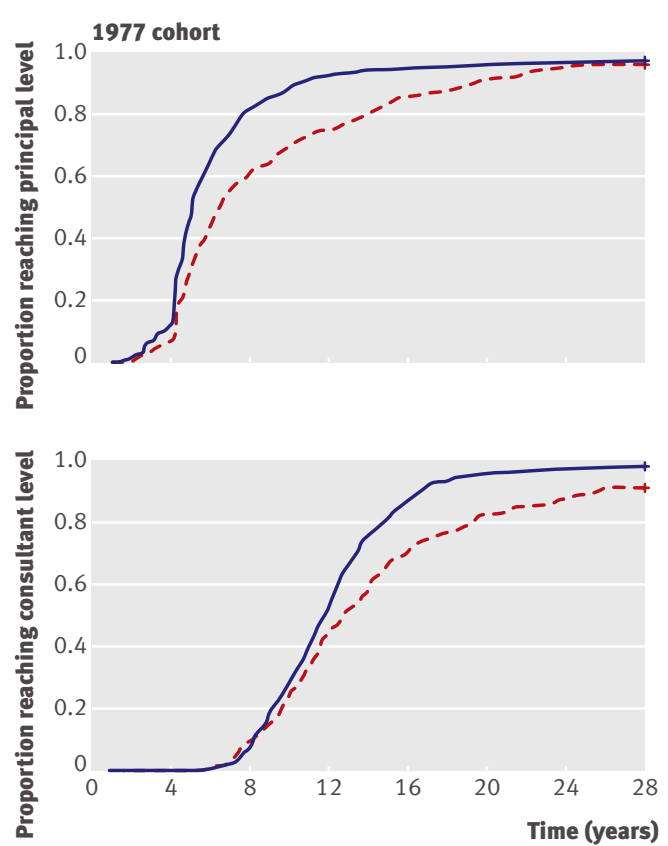

1988 cohort

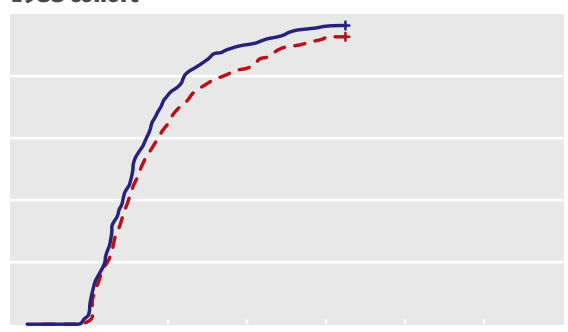

1993 cohort
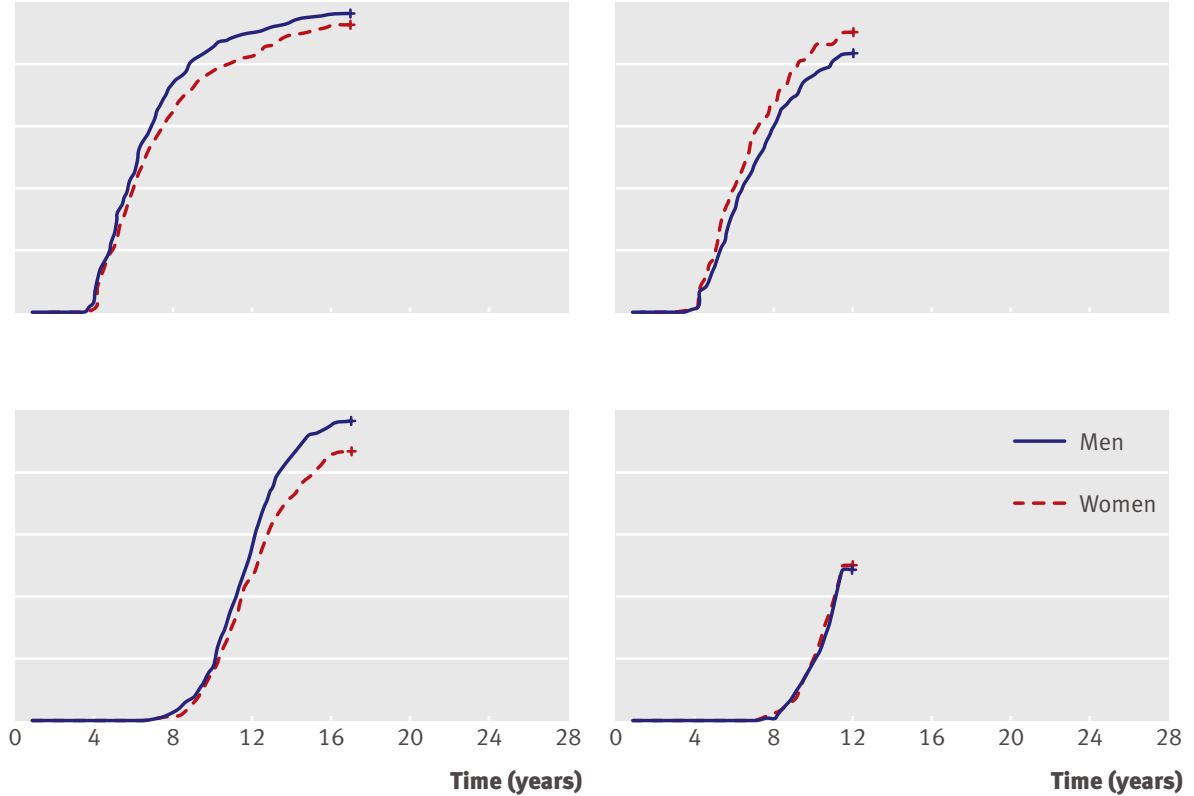

Fig 2 | Time after qualification to senior NHS posts, comparing men and women, split by cohort. +=censored 
who always worked full time during training, no significant differences existed between the men and women (table 4, fig 3). Median times from qualification to principal status were 5.8 (95\% confidence interval 5.6 to $6.0)$ years for men, 5.6 (5.4 to 5.8) years for women who had always worked full time during training, and 6.8 (6.5 to 7.0) years for all women. Median time to first consultant post was 11.7 (11.5 to 11.9$)$ years for men, 11.3 (11.0 to 11.6) years for women who worked full time during training, and 12.3 (12.0 to 12.6) years for all women.

We found few differences of any substance in the time to senior appointment when we compared women with and without children (table 5). In the 1993 cohort, many of whom had not reached consultant status, women without children in the fastest quarter achieved consultant status fractionally more quickly than did those with children (table 5). Considering the full timers during training (table 5, fig 4), both in general practice and in hospital practice (more significantly in the first), those with children progressed more quickly than those without children. The only significant differences between male and female full timers were in the progression to principal status for the 1988 cohort with no children and for the 1993 cohort with children.

\section{Time to first appointment as a hospital consultant by hospital specialty}

The time to appointment as a hospital consultant varied across the specialties (table 6). Doctors in surgical specialties and paediatrics took longer to reach consultant posts than others did, and those in anaesthetics achieved consultant posts more quickly than others did. Differences between specialties in their demographic composition (that is, confounding by sex or working pattern) did not account for the differences between specialties seen in the times to consultant appointment. The differences were still apparent when we made comparisons between the specialties considering only men, only women, and only women who had always worked full time during training (table 6).

For the 1993 cohort, for most specialties, less than $50 \%$ had become consultants so median times could not be calculated. Exceptions were anaesthetics (median times to consultant appointment: men 10.6, all women 11.0, women full time during training 10 . 8 years), psychiatry (men 10.4, all women 11.4, women full time during training 11.1 years), and pathology (men 10.5, all women 10.2, women full time during training 10.2 years).

\section{Career destinations}

The percentages in each specialty (table 7) differed significantly between men and women $\left(\chi^{2}=378.4, \mathrm{df}=11\right)$, between women who had always worked full time throughout their careers and men $\left(\chi^{2}=149.1, \mathrm{df}=11\right)$, between women who had worked full time and those who had worked part time $\left(\chi^{2}=197.0, \mathrm{df}=11\right)$, and between full time and part time working men $\left(\chi^{2}=88.0, \mathrm{df}=11\right)($ all $\mathrm{P}<0.001)$. This remained the case when we omitted general practice, public health medicine, and community health from the table $\left(\chi^{2}=266.4\right.$ 125.9, 30.9, and 35.6, df=10; all $\mathrm{P}<0.001)$

Table $\mathbf{5}$ |Years from qualifying as doctor to first appointment as NHS general practice principal or hospital consultant, split by having or not having children and working pattern during training. Values are median; fastest quarter (number)

\begin{tabular}{|c|c|c|c|c|}
\hline & \multicolumn{2}{|c|}{1988 graduates } & \multicolumn{2}{|c|}{1993 graduates } \\
\hline & Men & Women & Men & Women \\
\hline \multicolumn{5}{|l|}{ Achieved general practice principal status } \\
\hline All & $6.2 ; 5.1^{\star}(394)$ & $6.6 ; 5.2^{\star}(426)$ & $6.7 ; 5.2^{\star}(24) 1$ & $7.3 ; 5.6 *(302)$ \\
\hline With children & $6.1 ; 5.0^{*}+(347)$ & $6.6 ; 5.2^{*}(368)$ & $6.4 ; 5.1^{*}+(195)$ & $7.0 ; 5.4^{*}(215)$ \\
\hline No children & $9.6 ; 6.4^{*}+(47)$ & $6.4 ; 5.0 *(57)$ & $7.8 ; 6.3+(46)$ & $7.8 ; 6.2(87)$ \\
\hline Always worked full time and had children & $6.0 ; 5.0 \dagger(329)$ & 5.6; $4.6(210)$ & $6.0 ; 5.1^{*}+(75)$ & $5.5 ; 4.8^{*}+(129)$ \\
\hline Always worked full time and had no children & $8.8 ; 6.1^{*}+(39)$ & $6.1 ; 5.6^{\star}(42)$ & $7.1 ; 5.6 \dagger(39)$ & $7.3 ; 6.0 \dagger(57)$ \\
\hline Did not always work full time and had children & $8.2 ; 6.8(16)$ & $8.6 ; 6.5(157)$ & $9.7 ; 6.5(20)$ & $9.3 ; 7.0(83)$ \\
\hline Did not always work full time and had no children & $12.3 ; 9.6(8)$ & $7.9 ; 5.9(15)$ & $8.9 ; 7.8(7)$ & $8.2 ; 6.5(29)$ \\
\hline \multicolumn{5}{|l|}{ Achieved consultant status } \\
\hline All & $11.7 ; 10.4^{*} \ddagger(622)$ & $12.2 ; 10.6 *(363)$ & NC; 10.4 (313) & NC; 10.5 (208) \\
\hline With children & $11.6 ; 10.3^{*}+(515)$ & $12.5 ; 10.6 *(266)$ & $11.5 ; 10.3(223)$ & NC; 10.5 (109) \\
\hline No children & $12.0 ; 10.6 \dagger(105)$ & $12.1 ; 10.6 \ddagger(96)$ & NC; 10.5 (90) & $11.3 ; 10.2(99)$ \\
\hline Always worked full time and had children & $11.6 ; 10.3(507)$ & $11.0 ; 10.0 \dagger(160)$ & $11.5 ; 10.3(220)$ & $11.1 ; 9.9(73)$ \\
\hline Always worked full time and had no children & $11.9 ; 10.5(102)$ & $12.0 ; 10.5 \dagger(90)$ & NC; 10.5 (88) & $11.3 ; 10.1(98)$ \\
\hline Did not always work full time and had children & $14.0 ; 12.0(3)$ & $13.7 ; 12.0 \dagger(105)$ & NC; $10.3(3)$ & NC; $11.3(35)$ \\
\hline Did not always work full time and had no children & $16.0 ; 13.7(5)$ & NC; $15.1 \dagger(5)$ & NC; 9.4 (2) & NC; NC (1) \\
\hline
\end{tabular}

$\mathrm{NC}=$ median could not be calculated because $50 \%$ had not yet become consultants.

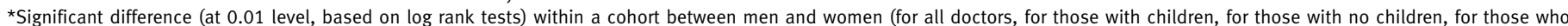

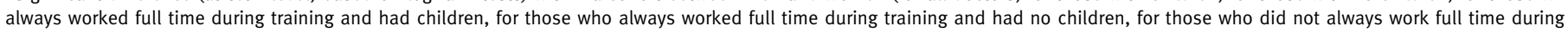
training and had children, and for those who did not always work full time during training and had no children).

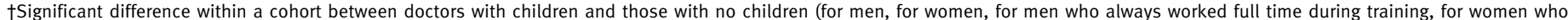
always worked full time during training, for men who did not always work full time during training, and for women who did not always work full time during training).

$\ddagger$ Significant difference within a cohort between women with no children and all men. 
Table 6 |Years from qualifying as doctor to first appointment as NHS hospital consultant, by hospital specialty. Values are median; fastest quartile (number)

\begin{tabular}{|c|c|c|c|c|c|c|c|c|}
\hline \multirow[b]{2}{*}{ Specialties* } & \multicolumn{4}{|c|}{1977 graduates } & \multicolumn{4}{|c|}{1988 graduates } \\
\hline & All & Men & Women & $\begin{array}{l}\text { Women always } \\
\text { full time } \dagger\end{array}$ & All & Men & Women & $\begin{array}{l}\text { Women always } \\
\text { full time } \dagger\end{array}$ \\
\hline Surgical specialties§ & $13.1 ; 11.5$ (176) & 13.2; 11.5 (168) & $12.7 ; 10.5(8)$ & 10.9; 9.7 (8) & $12.5 ; 11.5$ (183) & $12.4 ; 11.3(163)$ & $13.2 ; 12.4(20)$ & $12.5 ; 12.3(15)$ \\
\hline Medical specialties $\$ \S$ & $12.4 ; 10.6(174)$ & $12.3 ; 10.2(144)$ & $13.5 ; 11.8(30)$ & $12.5 ; 11.3(28)$ & $11.9 ; 10.7(220)$ & $11.8 ; 10.7(141)$ & $12.2 ; 10.7(79)$ & $11.2 ; 10.1(60)$ \\
\hline Anaesthetics $\ddagger$ & $10.1 ; 9.0(117)$ & $9.9 ; 8.6(93)$ & $13.1 ; 9.5(24)$ & $9.5 ; 9.2(17)$ & $11.0 ; 10.0(166)$ & $10.8 ; 9.9(108)$ & $11.3 ; 10.2(58)$ & $10.9 ; 10.0(43)$ \\
\hline Psychiatry§ & $11.1 ; 9.3(88)$ & $10.0 ; 8.4(48)$ & $12.2 ; 9.5(40)$ & $10.7 ; 9.2(25)$ & $11.5 ; 10.2(134)$ & $10.7 ; 9.6(59)$ & $12.0 ; 10.6(75)$ & $10.7 ; 9.8(40)$ \\
\hline Paediatrics & $12.8 ; 11.9(53)$ & $12.8 ; 12.0(32)$ & $13.4 ; 11.5(21)$ & $13.0 ; 11.3(15)$ & $12.1 ; 10.7(72)$ & $12.0 ; 10.2(35)$ & $12.4 ; 11.1(37)$ & $11.5 ; 10.2(23)$ \\
\hline Pathology & $11.1 ; 8.6(81)$ & $10.9 ; 8.5(56)$ & $11.5 ; 10.1(25)$ & $10.4 ; 7.9(18)$ & $11.0 ; 9.6(43)$ & $11.0 ; 9.6(26)$ & $11.4 ; 9.6(17)$ & $12.2 ; 9.5(12)$ \\
\hline
\end{tabular}

*Specialties with low counts (accident and emergency, obstetrics and gynaecology, clinical oncology and "other medical" specialties) excluded.

†Working pattern during training.

¥Significant differences (at 0.01 level, based on log rank tests) between men and women for 1977 graduates.

§Significant differences between men and women for 1988 graduates.

No significant differences existed between women who had worked full time during training and men in either cohort.

We identified the specialties that were significantly different, in each two column subset of table 7 , by examining adjusted standardised residuals. Significantly lower percentages of men than women were in psychiatry, paediatrics, obstetrics and gynaecology, clinical oncology, general practice, and "other medical" specialties. Significantly higher percentages of men than women were in surgical specialties, medical specialties, anaesthetics, and radiology. Significantly lower percentages of men than of women who had worked full time throughout their career were in psychiatry, paediatrics, obstetrics and gynaecology, clinical oncology, and other medical specialties. Significantly higher percentages of men than of full time working women were in general practice or in surgery. Significantly lower percentages of part time working women than of full time working women were in surgery, medical specialties, anaesthetics, pathology, obstetrics and gynaecology, and clinical oncology. Significantly higher percentages of part time working women than of full time working women were in general practice. Significantly lower percentages of part time working men than of full time working men were in surgery, medical specialties, anaesthetics, paediatrics, and clinical oncology. Significantly higher percentages of part time working men than of full time working men were in general practice and psychiatry.

Although relatively few men had ever worked part time, for completeness we also compared men and women who had always worked full time. The significant differences were in the same specialties as in the comparison between all men and full time working women. The specialty with the largest percentage of men who had worked part time was general practice (57\% of all part time working men).

The percentage of men who worked in surgery was substantially higher than that of full time working

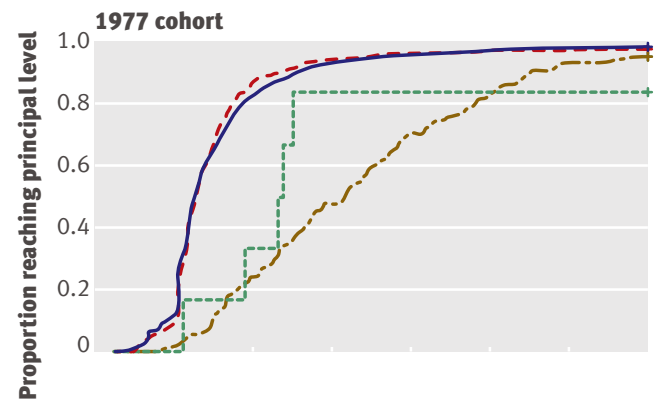

1988 cohort

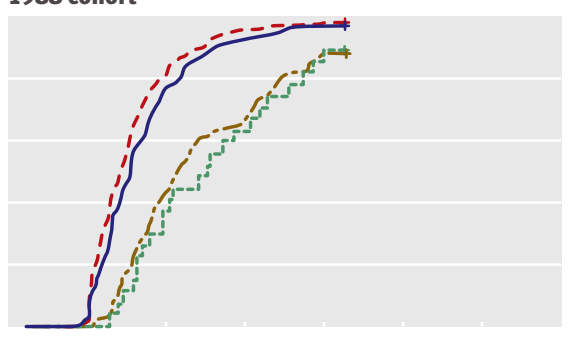

1993 cohort
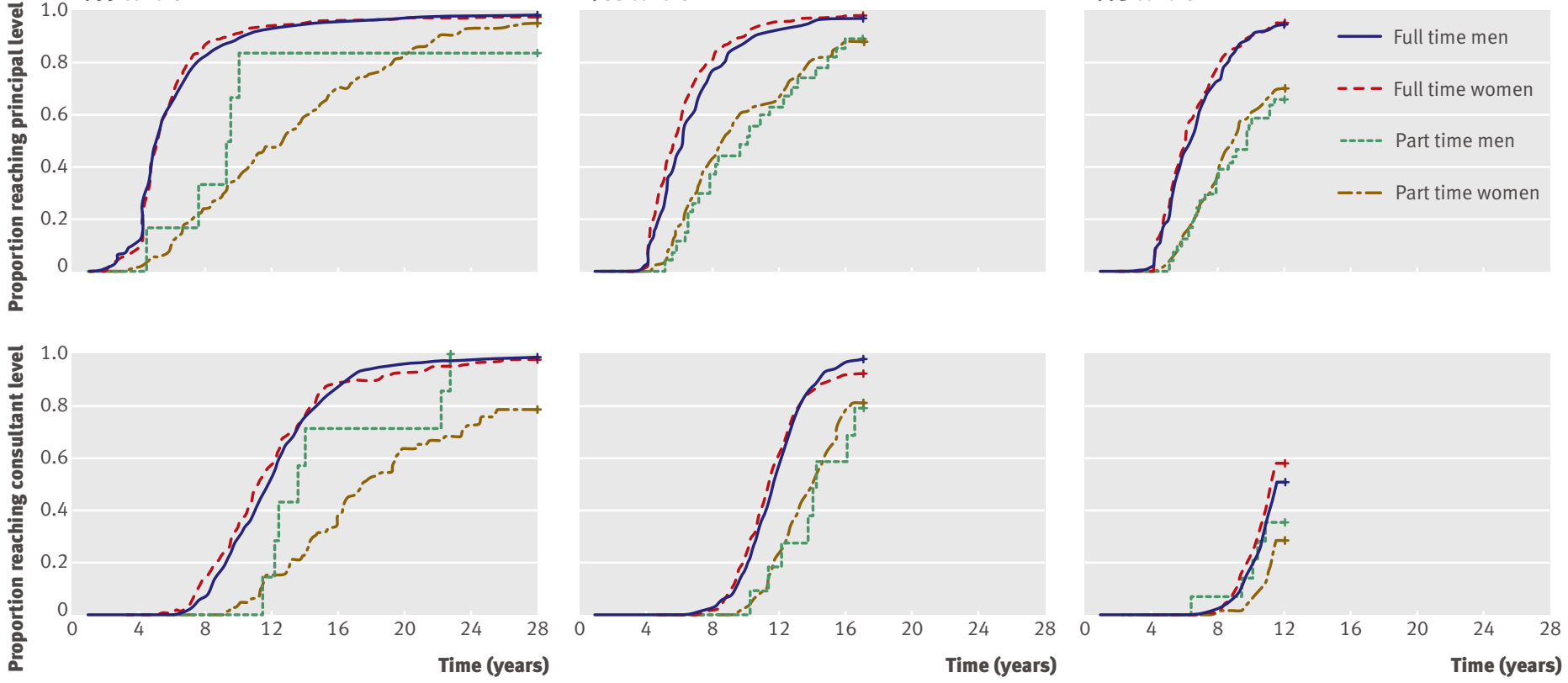

Fig $3 \mid$ Time after qualification to senior NHS posts, comparing full time working men, full time working women, part time working men, and part time working women, split by cohort. Full time and part time refer to working pattern during training. $+=$ censored 
women and part time working women $(16 \%, 6 \%$, and $2 \%$ ). Thus, the under-representation of surgeons among women doctors is not simply associated with part time working by women but is strongly associated with female sex itself. The percentages of men and of full time working women who worked in the hospital medical specialties were similar $(15 \%$ and $16 \%)$, but a lower percentage of part time working women worked in the hospital medical specialties (10\%). Anaesthetics was the career destination of similar percentages of men and full time working women $(9 \%$ and $10 \%)$ but a lower percentage of part time working women (4\%). Thus, the under-representation of hospital medical specialists and anaesthetists among female doctors is attributable to women having worked part time rather than to female sex itself. Psychiatry was the specialty destination of $5 \%$ of men, $9 \%$ of full time working women, and $8 \%$ of part time working women. Thus, the over-representation of psychiatrists among women doctors is attributable to female sex and not to women working part time. General practice was the destination of $37 \%$ of men, $31 \%$ of full time working women, and $56 \%$ of part time working women. Thus, the over-representation of general practitioners among female doctors is strongly associated with part time working by women.

\section{Comparison of specialties, excluding general practice}

For some doctors, the first and fundamental career choice may be whether to go into general practice. Some of the under-representation of women in hospital specialties is a consequence of the fact that a much
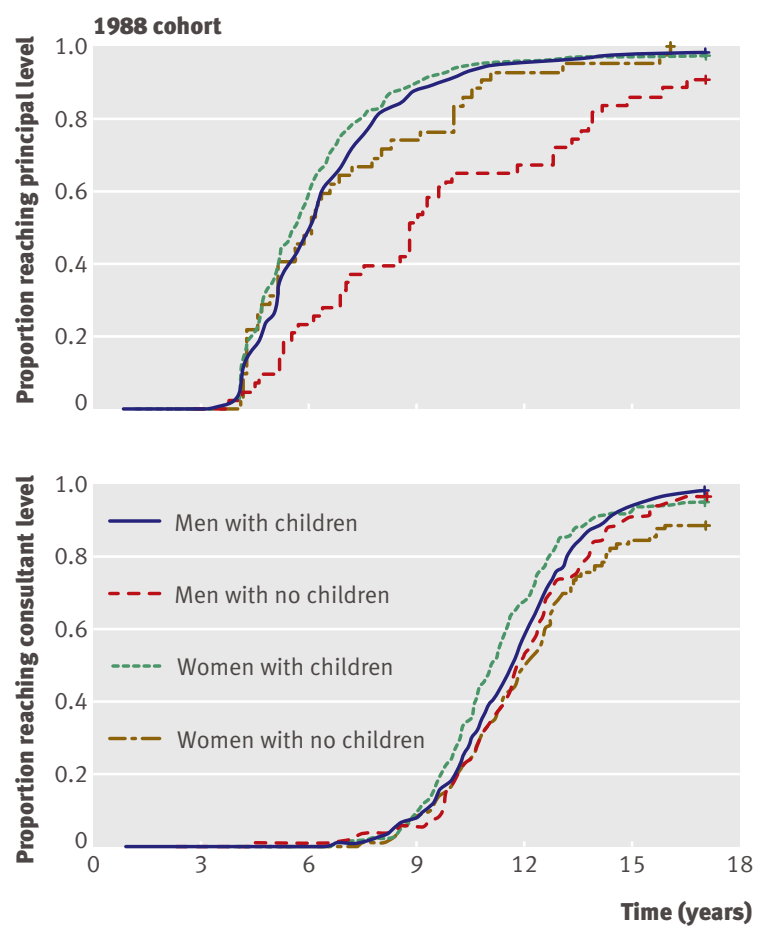

higher percentage of women than men enter general practice. Accordingly, we did further analyses excluding doctors in general practice. Excluding general practice, the under-representation of female doctors in surgery and anaesthetics was still evident, as was the over-representation of female doctors in psychiatry, paediatrics, obstetrics and gynaecology, and clinical oncology.

Comparing men with women who had worked full time, after excluding general practice, we still found significantly lower percentages of men than of full time working women in psychiatry, paediatrics, obstetrics and gynaecology, and clinical oncology. Radiology emerged as another specialty with a significantly lower percentage of full time working women than of men. The under-representation of full time working women in surgery was still apparent after excluding general practice.

After exclusion of general practice, women who had worked part time remained significantly under-represented, compared with full time working women, in surgery, anaesthetics, and obstetrics and gynaecology. After exclusion of general practice, psychiatry emerged as a specialty with a significantly higher percentage of women who had worked part time than of full time working women.

Comparing men who had worked full time and part time, after exclusion of general practice, part time working men remained significantly over-represented in psychiatry. Accident and emergency emerged as a further specialty with an over-representation of part time working men.
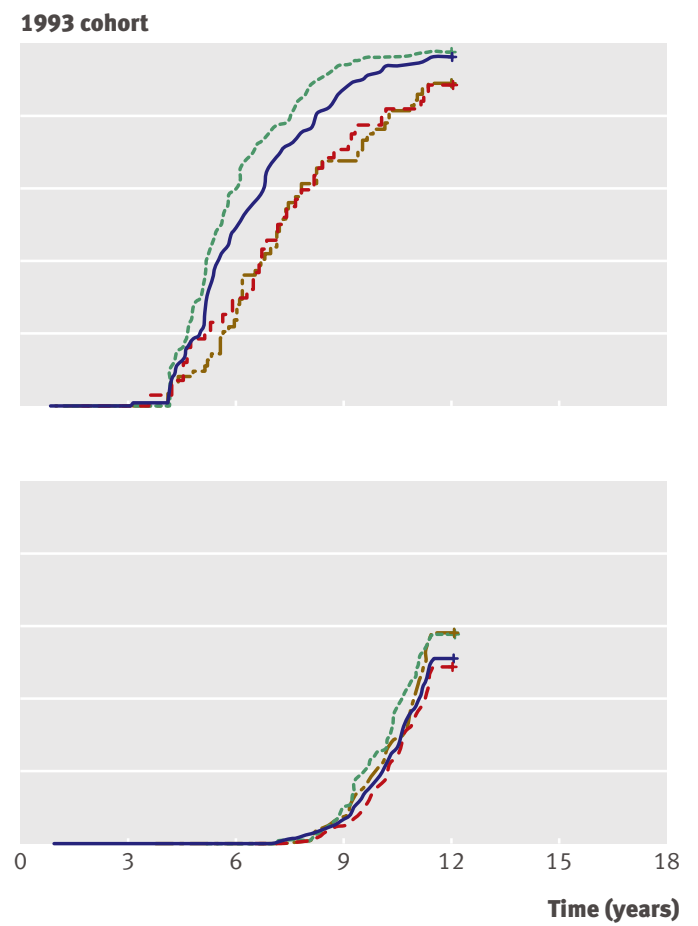

Fig 4 Time after qualification to senior NHS posts for those who always worked full time during training, comparing men with children, men without children, women with children, and women without children for 1988 and 1999 cohorts only. $+=$ censored 
Table $7 \mid$ Career destinations by specialty for NHS doctors for 1977, 1988, and 1993 cohorts combined: percentages (numbers) of men and women who worked in each branch of medicine

\begin{tabular}{|c|c|c|c|c|c|c|}
\hline & Men & Women & Men always full time & $\begin{array}{c}\text { Men not always full } \\
\text { time }\end{array}$ & Women always full time & $\begin{array}{c}\text { Women not always full } \\
\text { time }\end{array}$ \\
\hline General practice* $\dagger \ddagger \S$ & $37.0(1243)$ & $46.9(1248)$ & $34.8(1038)$ & $56.6(192)$ & $30.8(267)$ & $55.6(966)$ \\
\hline Surgical specialties* $† \ddagger \S$ & $16.1(542)$ & $3.5(93)$ & $16.8(501)$ & $9.7(33)$ & $6.1(53)$ & $2.2(39)$ \\
\hline Medical specialties $¥ £$ & $14.7(495)$ & $11.9(316)$ & $15.4(458)$ & $8.8(30)$ & $15.6(135)$ & $10.2(177)$ \\
\hline Anaesthetics ${ }^{\star} \mp \S$ & $9.3(311)$ & $6.3(167)$ & 9.9 (294) & $4.4(15)$ & $10.2(88)$ & $4.3(75)$ \\
\hline Psychiatry*†§ & $5.2(173)$ & $8.3(221)$ & $4.8(143)$ & $8.0(27)$ & $8.8(76)$ & $7.8(135)$ \\
\hline Paediatrics ${ }^{\star}+\S$ & $3.2(109)$ & $4.7(126)$ & $3.5(104)$ & $1.2(4)$ & $5.7(49)$ & $4.2(73)$ \\
\hline Pathology $\ddagger$ & $3.2(107)$ & $3.1(83)$ & 3.3 (99) & $2.1(7)$ & 4.5 (39) & $2.3(40)$ \\
\hline $\begin{array}{l}\text { Obstetrics and } \\
\text { gynaecology* } † \ddagger\end{array}$ & $2.3(76)$ & $3.1(82)$ & $2.4(72)$ & $1.2(4)$ & $5.4(47)$ & $2.0(34)$ \\
\hline Accident and emergency & $2.1(69)$ & $1.9(51)$ & $2.0(59)$ & $2.9(10)$ & $2.7(23)$ & $1.6(27)$ \\
\hline Clinical oncology ${ }^{\star} † \ddagger \S$ & $1.2(40)$ & $2.3(61)$ & $1.3(40)$ & $0.0(0)$ & $3.7(32)$ & $1.6(28)$ \\
\hline Radiology* & 3.3 (112) & $2.3(60)$ & $3.4(102)$ & $2.7(9)$ & $2.2(19)$ & $2.2(39)$ \\
\hline Other medical* $+\pi$ & $2.4(82)$ & $5.7(152)$ & $2.4(71)$ & $2.4(8)$ & $4.4(38)$ & $5.9(103)$ \\
\hline Total & $100.0(3359)$ & $100.0(2660)$ & $100.0(2981)$ & $100.0(339)$ & $100.0(866)$ & $100.0(1736)$ \\
\hline
\end{tabular}

Working pattern refers to that throughout the respondents' careers.

${ }^{*}$ Significant differences (based on analysis of adjusted residuals, P<0.01) between men and women.

†Significant differences between men and women who always worked full time.

$\ddagger$ Significant differences between women who always worked full time and women who did not always work full time.

$\S$ Significant differences between men who always worked full time and men who did not always work full time.

IIncludes other hospital specialties, public health medicine, and community health.

\section{DISCUSSION}

We found no evidence that women have been directly disadvantaged in their career progression in the NHS Although a smaller proportion of women than men progressed to senior posts, and men progressed more quickly than women to these posts, the career trajectories of women who had always worked full time were very similar to those of men. Men and women who had worked part time had broadly similar trajectories, which were slower than those of full time doctors. Thus the slower progression of women, overall, was attributable to the greater proportion of women than men who worked part time.

Women with and without children achieved senior status at approximately the same time, and the percentages of women with and without children who reached hospital consultant status were also similar. We found no evidence that having children disadvantaged the career progression of women who had always worked full time, either in the percentages who reached senior posts or in the speed with which they reached them.

Important differences existed, however, between men and women and between full time and part time working women in their specialty destinations. This may reflect the perceptions of women about specialties that are relatively easy, and those that may be not so easy, for women and for part time doctors to work in. The over-representation of women in general practice, and their under-representation in hospital practice, is wholly attributable to the high percentage of part time working women in general practice. Perhaps unexpectedly, women who had always worked full time were actually under-represented in general practice. Women were substantially under-represented in surgery overall, whether they were full time or part time workers. We found an over-representation of women in psychiatry whether the women had worked full time or part time.

\section{Strengths and weaknesses}

A strength of our study is that it is nationwide: we report on whole cohorts from all UK medical schools who qualified in the 1970s, 1980s, and 1990s, and the Kaplan-Meier "achievement analysis" incorporates data from all responders, including those who left the NHS and the UK. Although our response rates are good for questionnaire surveys of doctors, we cannot discount the possibility of responder bias: doctors who have had more successful careers, or perhaps those who feel that they have had less successful careers, may be more likely to respond to the invitation to participate.

We had to use data on doctors who qualified many years ago, because the investigation was of attainment of seniority. The career trajectories of these cohorts may differ from those who qualified in more recent years, who will benefit from reductions in working hours, the implementation of the European Working Time Directive, ${ }^{2324}$ and the reforms to specialist training, ${ }^{23}$ but this is not yet known.

Our data did not include precise information on the timing of the birth of children in relation to the respondents' careers. Hence we could not "adjust" the analysis in the same way as for part time working - in other words, to allocate responders to the "no children" group only if they were childless until they had reached consultant or general practice principal status.

We could have used other career milestones in addition to the achievement of principal or consultant status, but we doubt that this would have much altered our main conclusions. We do not have detailed information 
from women who had not always worked full time about the duration of career breaks, part time work, or how many hours or sessions they worked when part time.

Our response rates are high for self completed questionnaires. Our lower response rate among men is consistent with other studies.

\section{Comparison with other studies}

Our findings are consistent with other comparable research in the UK. For example, a BMA report provided illustrations of the existence of sex disparity within medicine - the under-representation of women in various specialties ${ }^{4}$ - and our survey data show such disparities. Our findings of no direct barriers to the career progression of women support the findings from a study of the early careers of British medical graduates of 1981-7, which found no disadvantages for women in the competition for early career posts. ${ }^{25}$ Like McManus and Sproston, ${ }^{20}$ we found little or no statistical evidence of discrimination against women in the NHS.

A study in Scotland showed some evidence of differences in promotion rates by sex after adjustment for other factors, including part time working (only part time working in the preceding two years was recorded).$^{26}$ However, as it was concerned with modelling short term promotions from one year to the next, its results may have been substantially influenced by short term movements of women in and out of the workforce for family reasons.

\section{Unanswered questions and future research}

Our study lacks detail about doctors' personal circumstances. We have no information about whether women who worked full time typically had to make greater sacrifices than men did in order to achieve similar career progress. For example, a significantly lower percentage of women than of men in hospital practice had children. This might reflect a choice made by some women between their career and parenthood. A career in hospital practice may, however, be favoured by women who never intended to have children. A study of career related personal sacrifices, comparing men and women, is a possible area for future work.

Although our data indicate that no systematic direct discrimination exists against women in the NHS, indirect discrimination may remain and might include factors noted by other authors such as working conditions that conflict with family life, ${ }^{9}$ lack of suitable role models, and patronage that favours men. ${ }^{814}$ Future research could seek to identify potential impediments to women's progress, to establish their relative importance, and to establish whether past impediments still exist.

Full time working women were under-represented in general practice. One explanation for this is that women who intended always to work full time may be less likely than others to want a career in general practice. Another possibility is that some women who choose hospital careers may decide that they must work full time in order to succeed.

We cannot tell whether differences in women doctors' specialty destinations, compared with those of men, particularly the low percentages of women in the surgical specialties, have resulted from indirect barriers to women or from women's professional preferences. ${ }^{1227}$ Ensuring that no remediable aspects of the work or culture of the specialties exist that deter women who might otherwise have been attracted to them is important. ${ }^{26}$ A comparison of actual career outcomes with preferences at graduation would offer some insight into whether career destinations are actual choices or reflect lack of choice. Such work is underway and will form part of a future article.

Doctors were only included in our analysis for as long as they remained in the NHS following graduation. Periods of service back in the NHS following departure and then a return did not contribute to the calculations. Extending the analysis to incorporate these periods of working would be more complete but would need a more complex analysis beyond the scope of this paper.

Our findings do not necessarily apply to the promotion of women in academic medicine. A body of evidence suggests that women working in academic medicine are disadvantaged both directly and indirectly. ${ }^{15-1928-30}$ Academic doctors who work part time have the inevitable challenge of striving to achieve at high levels in the three areas of research, teaching, and clinical practice.

Further research could investigate the finding that doctors without children progressed more slowly to principal posts than did those with children. A greater number of doctors without children may be taking on non-principal roles; becoming a principal is associated with longer term stability in terms of location and employment, which may be more desirable for those with children.

Further studies could consider the career progression of women within different healthcare systems and within different professions. For example, the challenges of women achieving promotion within medicine could be placed in context with the challenges faced by women in the public sector more generally or within science as a whole. ${ }^{3132}$

\section{Policy implications}

Most hospital consultants are men. Many are graduates from a time when medical schools were male dominated. Women now comprise $60 \%$ of medical school intake. Many women, needing to balance work with family commitments, opt to work part time. This means that a larger proportion of the future medical workforce will work part time. These doctors need adequate support to reach their full potential and to ensure that career progression is based on merit and capability rather than personal and domestic circumstances. ${ }^{334}$

Flexible working options, with good opportunities for training and career progression, with support for an improved work-life balance, and with good quality, 


\section{WHAT IS ALREADY KNOWN ON THIS TOPIC}

Reports of impediments to female doctors' career progression have tended to focus on US studies and academic medicine

Sex disparity in specialty destinations may in part reflect the effects of male patronage, a lack of female role models, or working circumstances that conflict with family life

Disparity in the time taken to achieve senior positions may reflect several factors, including not having always worked full time

\section{WHAT THIS STUDY ADDS}

In the NHS, the fact that women progressed less far and less fast than men was generally a result of not having always worked full time rather than of female sex

Direct discrimination by sex seems unlikely, but given the differences between men and women in their specialty destinations the possibility of indirect discrimination cannot be ruled out

An equitable system for training, working, and promotion should consider the needs of doctors who wish to work part time and take career breaks as well as those who do not

affordable, and accessible child care, are needed. ${ }^{4-6833}$ These needs are recognised by the British government in its "improving working lives" standard, ${ }^{35}$ which summarises the commitment that is expected from NHS employers, in the Royal College of Physicians' recommendations for more part time working opportunities, and in the Royal College of Surgeons' "women in surgery" initiative, which provides support for flexible training. ${ }^{6}$ Associated challenges include the calls to extend the duration of training for general practice, ${ }^{36}$ to enable general practitioners to gain the additional skills for their extended roles that will result from the reconfiguration of health services, shifting towards less hospital based and more community based care. ${ }^{37}$ Increasing part time working will also provide some solutions to enable workforce planners to comply with the European Working Time Directive. ${ }^{2324}$

As well as shifts from full time to part time working, movement in the opposite direction may also occur. Women may be encouraged to train full time by the changes associated with the European Working Time Directive and the reduction of training periods as a result of the "Modernising Medical Careers" initiative. ${ }^{232436}$

Direct discrimination in training and employment, on the grounds of sex, is now illegal in the UK. Real barriers to women in medicine undoubtedly existed in the past. The fact that, historically, so many fewer women than men entered medical school indicates that this must have been so. Impediments to progress by women, in the past, must also account for the underrepresentation of women at consultant level in some specialties now.

\section{Conclusion}

Female sex itself is not now a direct barrier to the career progress of doctors in the NHS. We cannot rule out the possibility that it may, in some respects, be an indirect barrier. In particular, it is now important to ensure that women who wish to work part time do not encounter barriers to career progression, such as inflexible career structures.

We are very grateful to each doctor who participated. We thank Janet Justice and Alison Stockford for their careful data entry and Emma Ayres for survey administration.

Contributors: TWL and MJG designed the study. KST analysed the data and wrote the first draft. All the authors contributed to further drafts, and all are guarantors.

Funding: The UK Medical Careers Research Group is funded by the policy research programme, Department of Health. The Unit of Health Care Epidemiology is funded by the NIHR Co-ordinating Centre for Research Capacity Development. The study sponsors did not have a role in the design, conduct, analysis, or reporting of the study. The views and opinions expressed in the paper do not necessarily reflect those of the sponsors.

Competing Interests: None declared

Ethical approval: The Brighton and Mid Sussex Research Ethics Committee approved the UK Medical Careers Research Group's surveys and studies, in its role as a multi-centre research ethics committee (REC 04/Q1907/48)

1 Medical Manpower and Education Division. Medical and dental staffing prospects in the NHS in England and Wales in 1987. Health Trends 1988;4(20):101-9.

2 Department of Health. Hospital doctors: training for the future. The report of the working group on specialist medical training. London: Department of Health, 1993.

3 Calman KC, Temple JG, Naysmith R, Cairncross RG, Bennett SJ. Reforming higher specialist training in the United Kingdom-a step along the continuum of medical education. Med Educ 1999;33:28-33.

4 Equal Opportunities Committee. Career barriers in medicine doctors' experiences. London: British Medical Association, 2004.

5 Chief Medical Officer. Women in medicine: opportunity blocks. In: On the state of public health: annual report of the Chief Medical Officer 2006. London: Department of Health, 2007.

6 Fitzgerald RC, Black C. Women in hospital medicine: career choices and opportunities. Hosp Med 2001;62:778-9.

7 Valian V. Why so slow? The advancement of women. Cambridge, MA: MIT Press, 1999.

8 Allen I. Women doctors and their careers: what now? BMJ 2005;331:569-72.

9 Jackson C, Ball J, Hirsch W, Kidd M. Informing choices: the need for career advice in medical training. London: National Institute for Careers Education and Counselling, 2002.

10 Lambert TW, Goldacre MJ, Edwards C, Parkhouse J. Career preferences of doctors who qualified in the United Kingdom in 1993 compared with those of doctors qualifying in 1974, 1977, 1980, and 1983. BMJ 1996;313:19-24.

11 Reed V, Buddeberg-Fischer B. Career obstacles for women in medicine: an overview. Med Educ 2001;35:139-47.

12 Williams C, Cantillon R. A surgical career? The views of junior women doctors. Med Educ 2000;34:602-7.

13 Timmis AD, English KM. Women in cardiology: a UK perspective. Heart 2005;91:273-4

14 Currie C. Role models and patronage. BMJ 1993;306:735-6.

15 Hamel MB, Ingelfinger JR, Phimister E, Solomon CG. Women in academic medicine-progress and challenges. N Engl J Med 2006;355:310-2.

16 Colletti LM, Mulholland MW, Sonnad SS. Perceived obstacles to career success for women in academic surgery. Arch Surg 2000;135:972-7.

17 Kaplan SH, Sullivan LM, Dukes KA, Phillips CF, Kelch RP, Schaller JG. Sex differences in career advancement. $N$ Engl / Med 1996;335:1282-9.

18 Sonnad SS, Colletti LM. Issues in the recruitment and success of women in academic surgery. Surgery 2002;132:415-9.

19 Carr PL, Szalacha L, Barnett R, Caswell C, Inui T. A "ton of feathers": gender discrimination in academic medical careers and how to manage it. J Womens Health 2003;12:1009-18.

20 McManus IC, Sproston KA. Women in hospital medicine in the United Kingdom: glass ceiling, preference, prejudice or cohort effect? J Epidemiol Community Health 2000;54:10-6.

21 McKinstry B, Colthart I, Elliott K, Hunter C. The feminization of the medical workforce, implications for Scottish primary care: a survey of Scottish general practitioners. BMC Health Serv Res 2006;6:56.

22 Altman DG, Bland JM. Time to event (survival) data. BMJ 1998;317:468-9.

23 Statutory Instrument 1998 No 1833: the working time regulations 1988. London: Stationery Office, 1998. 
24 Statutory Instrument 2003 No 1684: the working time regulations 2003. London: Stationery Office, 2003.

25 McKeigue PM, Richards JDM, Richards P. Effects of discrimination by sex and race on early careers of British medical graduates during 1981-7. BMJ 1990;301:961-4.

26 Mavromaras K, Scott A. Promotion to hospital consultant: regression analysis using NHS administrative data. BMJ 2006;332:148-51.

27 Goldacre MJ, Willett K, Lambert TW. Career choices for trauma and orthopaedic surgery: 30 years of surveys. Ann R Coll Surg Engl 2008;90(suppl):134-8.

28 Ash AS, Carr PL, Goldstein R, Friedman RH. Compensation and advancement of women in academic medicine: is their equity? Ann Intern Med 2004;141:205-12.

29 Killaspy H, Johnson S, Livingston G, Hassiotis A, Robertson M. Women in academic psychiatry in the United Kingdom. Psychiatr Bull 2003;27:323-6.

30 Sandhu B, Margerison C, Holdcroft A. Women in the UK academic workforce. Med Educ 2007;41:909-14.
31 Dex S. Women's occupational mobility: a lifetime perspective. London: Macmillan, 1987.

32 Bebbington D. Women in science, engineering and technology: a review of the issues. High Educ Quart 1990;56:360-75.

33 Educating Tomorrow's Doctors Working Group. Educating tomorrow's doctors-future models of medical training; medical workforce shape and trainee expectations. London: Postgraduate Medical Education Training Board, 2008.

34 Dacre J. Are there too many female medical graduates? No. $B M$ 2008;336:749.

35 Department of Health. Improving working lives for doctors. London: Department of Health, 2001.

36 Tooke J. Aspiring to excellence: findings and final recommendations of the Independent Inquiry into Modernising Medical Careers. London: MMC Inquiry, 2007.

37 NHS Employers. The future of the medical workforce. London: N HS Employers, 2007. (Discussion paper, issue 1.)

Accepted: 28 January 2009 